\title{
Physical activity, mental and personal wellbeing, social isolation, and perceptions of academic attainment and employability in university students: Pooled analysis of the Scottish and British Active Students Surveys Pre-print article published on: 16 th $^{\text {th }}$ August 2019 doi: 10.31236/osf.io/xaum3
}

Research conducted by the ukactive Research Institute

Article under review in Journal of Physical Activity and Health Citation: Budzynski-Seymour, E., Conway, R., Wade, M., Lucas, A., Jones, M., Mann, S., \& Steele, J. (2019). Physical activity, mental and personal wellbeing, social isolation, and perceptions of academic attainment and employability in university students: Pooled analysis of the Scottish and British Active Students Surveys.

https://doi.org/10.31236/osf.io/xaum3 


\section{SUMMARY OF KEY FINDINGS}

- Physical activity (PA) is well accepted as a means of improving both physical and psychological health and wellbeing, and reducing risk of non-communicable diseases. Although children and adolescents are typically more likely to meet guidelines for PA compared with adults, there is a substantial decrease in PA during the transition into young adulthood.

- This has primarily been attributed to changing environments and priorities such as those involved in Higher Education. Whilst not all young people enter Higher Education approximately a third of 18 year olds in the UK do so.

- Prior research from the Student Activity and Sports Participation Survey Ireland found that university students meeting the PA guidelines were more likely to report greater overall health, mental wellbeing and happiness than inactive peer.

- The ukactive Research Institute has previously conducted similar surveys in Scotland and the UK in general - the Scottish Active Student Survey (SASS), and British Active Student Survey (BASS) - and here we present analysis of the relationships between PA, physical and mental wellbeing, and perceptions of attainment and employability, in a large sample $(n=11,650)$ of UK students from these two surveys.

- Only $51 \%$ of students met currently recommended levels of moderate to vigorous PA per week, and there was linear relationship between PA levels and all outcomes. Students with higher levels of PA typically had better scores for physical and mental wellbeing, and perceptions of attainment and employability.

- Compared with data from the general population of 16-24 year olds, UK university students are insufficiently active. Yet, those students who report higher levels of PA also report better mental and personal wellbeing, social isolation, and perceptions of academic attainment and employability.

- Considering the important transitional period university represents, approaches to facilitate engagement in PA in students should be considered by Higher Education Institutions. Indeed, university settings have been suggested to be appropriate for implementation of lifestyle interventions such as PA. 


\title{
Physical activity, mental and personal wellbeing, social isolation, and perceptions of academic attainment and employability in university students: Pooled analysis of the Scottish and British Active Students Surveys
}

\author{
Budzynski-Seymour, E..$^{\mathrm{a}}$, Conway, R. ${ }^{\mathrm{a}}$, Wade, M. ${ }^{\mathrm{b}, \mathrm{c}}$, Lucas, A. ${ }^{\mathrm{b}, \mathrm{d}}$, Jones, M. ${ }^{\mathrm{e}}$, Mann, S. ${ }^{\mathrm{f}}$, and Steele, J. ${ }^{\mathrm{a}, \mathrm{b}}$
}

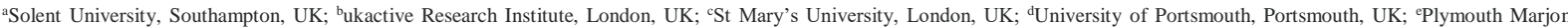
University, Plymouth, UK; fPlaces for People Leisure, UK; Contact for Correspondence emily.budzynski-seymour@solent.ac.uk; jamessteele@ukactive.org.uk; Twitter: @Emily_CBS; $@$ jamessteeleii

\section{SCIENTIFIC ABSTRACT}

Background: Achieving sufficient physical activity (PA) promotes health and wellbeing. For students, university represents a transitional period including increased independence over lifestyle behaviors, in addition to new stressors and barriers to engaging in PA. It is therefore important to monitor PA trends in students to gain a greater understanding about the role it might play in physical and mental wellbeing, as well as other factors such as attainment, and employability. Methods: Cross-sectional surveys were conducted in 2016 in Scottish universities and colleges (SASS) and 2017 in universities and colleges across the UK (BASS) and data were pooled for the present study $(n=11,650)$. Cumulative ordinal logistic regression was used to model the association between PA levels and mental and personal wellbeing, social isolation, and perceptions of academic attainment and employability. Results: Only $51 \%$ of respondents met recommended levels of moderate to vigorous PA per week. There was a linear relationship between PA levels and all outcomes with better scores in more active students. Conclusions: UK university students are insufficiently active compared with the general population of 16-24 year olds. Yet, students with higher PA report better outcomes for mental and personal wellbeing, social isolation, and perceptions of academic attainment and employability.

Key words: physical activity; education; undergraduate; postgraduate; sports; health; wellbeing

\section{INTRODUCTION}

Sufficient physical activity (PA) is well accepted as a means of improving health and preventing non-communicable disease conditions ${ }^{1,2}$. In addition, PA has been argued to be a means to enhance various aspects of emotional health and produce psychological benefits ${ }^{3}$. A key element of health promotion in many countries therefore includes strategies to increase PA levels to meet the recommended guidelines. Despite children and adolescents being more likely to meet PA recommendations than adults ${ }^{4.5}$, research has identified a substantial decrease in PA during the transition from adolescence to young adulthood ${ }^{6}$. The proportion of young adults (18-24 years) achieving PA recommendations is much lower than that of adolescents (11-17 years), which may be attributed to changing environments and priorities resultant from undertaking further education (e.g. college and university studies $^{7}$ ). This period of transition for young adults can be key as the development and maintenance of positive health behaviours during this age has been argued to lead to sustained behaviours and improved health into adulthood ${ }^{8}$. Furthermore, a lack of PA is one of the top three modifiable risk factors for many chronic diseases and therefore increasing levels of PA at this crucial stage in a person's life can help increase the health of the emerging adult population ${ }^{8}$.

Whilst not all young people proceed to Higher Education, in the UK approximately one third of 18 year olds continue on to this level of education after school and further education ${ }^{9}$. The transition to higher education is associated with increased independence over lifestyle and dietary habits ${ }^{10}$. Yet, it is relatively uncommon for students to consider the long term risk of developing chronic diseases when making behaviour choices ${ }^{7}$, despite it 
being established that PA is clearly linked with morbidity risk ${ }^{11}$, During university life students face a combination of individual agency factors (i.e. decision making), social factors (i.e. influence of friends) and physical factors (i.e. accessibility and availability) that contribute to decreased PA and an increase in emotional and psychological stress ${ }^{12,13}$. In turn, specific stressors can lead to a further decline in PA including; change of residence, increasing responsibility, peer pressure, coursework management, and difficult schedules ${ }^{12}$. Students also spend a high percentage of time performing sedentary activities (e.g. sitting in class and at a computer, on social media, and studying), thus giving students the perception of reduced time to engage in $\mathrm{PA}^{13}$. Students who meet the recommendations from the Chief Medical Officers' (CMO) Guidelines for $\mathrm{PA}^{14}$ tend to engage in wider healthy behaviours ${ }^{15,16}$, and the potential role of PA within all domains (work, transport, domestic, and leisure-time) has been positively associated with health-related quality of life in students ${ }^{17}$. Though students have not always been aware of the benefits of meeting PA recommendations ${ }^{18}$, recent work suggests that PA levels, along with dietary habits, are recognised by students as being important, yet still recommendations for these lifestyle behaviours are rarely implemented in practice ${ }^{19}$.

Limited engagement in PA not only acts as a contributor to decreased physical health in students but it is also associated with indicators of poorer mental health and wellbeing, increased risk of depression, and weaker cognitive functioning ${ }^{3,8,13}$. There is also an emerging body of evidence that suggests that regular engagement in PA may have cognitive effects and is associated with improved academic attainment in adolescents ${ }^{20}$. This in turn may result in improved graduate employment and longer-term employability $^{21,22}$. Though there is less data on this relationship specifically in young adults attending university with respect to
PA generally, what is available argues that sport positively impacts upon graduate employability ${ }^{23}$.

It is clear that the collective benefits of engagement in PA, particularly in young adults, have the potential to positively impact an individual's physical and mental wellbeing ${ }^{25}$. It is therefore important to monitor PA trends in students and to gain a greater understanding about the role it might play in physical and mental wellbeing, attainment, and employability ${ }^{18}$. The recent (2014-2015) Student Activity and Sports Participation Survey Ireland (SASSI) sampling 8,122 students, reported that those meeting the PA guidelines were more likely to report greater overall health, mental wellbeing, and happiness than inactive peers ${ }^{25}$. Two similar surveys have also recently been conducted in both Scotland, and across the UK in general; the Scottish Active Student Survey (SASS) and British Active Student Survey (BASS). As such, the aim of the present study was to examine PA levels of students and explore the relationships between PA, physical and mental wellbeing, perceptions of attainment, and perceptions of employability, in a large sample of UK students using pooled data from both the SASS and BASS.

\section{METHODS Design}

Cross-sectional surveys were conducted in 2016 in Scottish universities and colleges (SASS) and 2017 in universities and colleges across the UK (BASS). Respondents were entered into a raffle (prizes ranged from a $£ 219.00$ activity tracker to $£ 50.00$ shopping vouchers) as an incentive to complete the survey. Both the SASS and BASS surveyed students on their PA level, mental wellbeing, social isolation, and perceived attainment and employability. Data from these two surveys were pooled for secondary analysis. Replicate data from Scottish university students participating in both surveys were identified and removed 
with the most recent survey data kept. For the purposes of the present analysis only data from university students were examined. The aim was to examine the relationships between PA levels and other outcomes measured in the surveys. Ethical approval to conduct the present secondary analysis was granted by the Health, Exercise, and Sport Science Ethics Committee at the senior authors academic institution (Id No: steej2019).

\section{Sample}

The full combined data sets from the SASS and BASS contained student's data from respondents across 117 further and higher education institutions in the UK. Data from further education institutions were excluded $(n=769)$ leaving a sample size of 11,650 undergraduate and postgraduate students from higher education institutions. Table 1 contains descriptive demographics of the sample. Surveys were disseminated through institution direct emails, social media platforms, and face-to-face engagement. All respondents gave informed consent to participate in the survey and for their anonymized data to be used for research purposes including the conduct of future studies and publication of the findings from these studies.

\section{Survey measures}

PA was examined via self-report using a modified single item minute based activity question ${ }^{26}$ which aligned with Sport England's measure of PA permitting comparison with their Active Lives survey $^{27}$. Participants were asked "In the past week, how much moderate intensity physical activity have you completed in total?" and answered with either under 30 minutes, 31-90 minutes, 90-149 minutes, or $150+$ minutes. Moderate intensity physical activity was clarified as "...activity you do that gets you out of breath or raises your heart beat - this is called moderate intensity activity. This may include sport, exercise, and brisk walking or cycling for recreation or to get to and from places, but should not include housework or physical activity that may be part of your job". From this, participants were grouped into three categories based upon their total weekly PA: "Inactive" (under 30 minutes), "Fairly active" (31-90 minutes and 90-149 minutes), and "Active" (150+ minutes). Participants were also asked how much time they had spent sitting on weekdays during the last 7 days including time spent at work, at home, while doing course work, and during leisure time.

Mental wellbeing was examined via self-report using the Short WarwickEdinburgh Mental Wellbeing scale ${ }^{28}$, which is a shortened (7 of the 14 items) version of the full Warwick-Edinburgh Mental Wellbeing scale ${ }^{29,30}$. The score for items is transformed to a metric value and the score reflects primarily functioning as opposed to feeling ${ }^{31}$. The WarwickEdinburgh Mental Wellbeing scale has previously been used in populations of students $^{32}$ similar to those included in the SASS and BASS. Mental wellbeing scores were categorized as an ordinal variable with the categories of 'low' (7 to 19.3), 'medium' (20.0 to 27.0), and 'high' (28.1 to $35)$ based upon means and standard deviations from The Health Survey for England $^{33}$.

Personal wellbeing was examined using the Personal Wellbeing 4 questions from the Office for National Statistics ${ }^{34}$. The questions were scored on an 11-point Likert scale ( 0 to 10) measuring life satisfaction ("Overall, how satisfied are you with your life nowadays?"), worthwhileness ("Overall, to what extent do you feel that the things you do in your life are worthwhile?"), happiness ("Overall, how happy did you feel yesterday?"; a higher score indicates a more positive answer), and anxiety ("Overall, how anxious did you feel yesterday?"; a lower score indicates a more positive answer). Personal wellbeing scores were categorized as an ordinal variable with life satisfaction, worthwhileness, and 
happiness as 'low' (0 to 4$)$, 'medium' (5 to 6), 'high' (7 to 8), and 'very high' (9 to 10), and anxiety as 'very low' (0 to 1$)$, 'low' (2 to 3), 'medium' (4 to 5), and 'high' (6 to 10) according to thresholds used in the Personal Wellbeing Across the UK survey ${ }^{35}$.

Social isolation was examined using the PROMIS Social Isolation 4a questions ${ }^{36}$ which consists of four items: "I feel left out," "I feel that people barely know me," "Ifeel isolated from others," and "I feel that people are around me but not with me." Each item is scored on a 5-point Likert scale, with the response options of "Never," "Rarely," "Sometimes," "Usually," and "Always. Scores could range from 4 to 20 , with a higher score indicating greater perceived social isolation. These scores were converted to a metric $T$ score ranging from 34.8 to 74.2 centered on a score of 50 with a standard deviation of 10. Social isolation scores were categorized as an ordinal variable with the categories of 'low' $(<40)$, 'medium' (40 to 60), and 'high' $(>60)$ based upon previous population normative data ${ }^{37}$.

Perceptions of academic attainment were examined via self-report by asking respondents what grade they expected to achieve at the end of this year (for undergraduates $-3^{\text {rd }}, 2: 2,2: 1,1^{\text {st }}$, or Too early to say; for postgraduates - Pass, Merit, Distinction, or Too early to say, and postgraduates were also asked what they achieved for their undergraduate degree). For the purposes of analysis, we removed those participants who at the time of survey answered "Too early to say" $(n=4244)$.

Perceptions of employability were examined using a range of questions. This included confidence that they will be employed within six months of graduation (scored 1 [not at all confident] to 5 [very confident]) and their agreement with a range of statements relating to key employability skills (scored as 1 [not at all] to 5 [very] how well they felt they met these skills based on statements provided) including verbal communication ("You are able to express your ideas clearly and confidently in speech"), teamwork ("You work confidently in a group"), commercial awareness ("You are able to understand the commercial realities affecting an organization"), analyzing and investigating ("You can gather information systematically to establish facts and principles"), initiative/self-motivation ("You are able to act on initiative, identify opportunities and you are proactive in putting forward ideas and solutions"), drive ("You have a determination to get things done. Make things happen and you are constantly looking for better ways of doing things"), written communication ("You are able to express yourself clearly in writing"), planning and organizing ("You are able to plan activities and carry them through effectively"), flexibility ("You can adapt successfully to changing situations and environments") and time management ("You manage time effectively, prioritizing tasks and are able to work to deadlines"). Questions were also asked regarding the extent to which respondents felt that participation in PA and/or sport improves employability and whether they would refer to this when applying for jobs (scored 1 [not at all] to 5 [it's the most important factor]).

Lastly questions were also asked regarding whether respondents were currently members of gyms and/or sports clubs (yes or no), whether they were aware of the current CMO Guidelines for PA (yes or no), whether they currently were employed in part time work alongside their studies (yes or no), and how many hours per week they spent studying and in classes $(<5$ hours, 5-10 hours, 10-15 hours, 15-20 hours, 20-25 hours, 25-30 hours, or $>30$ hours).

\section{Statistical analysis}

Statistical analysis was performed using cumulative ordinal logistic regression to model the association between the independent ordinal variable PA level ('inactive' $=0$, 'fairly active' $=1$, and 'active' $=2$ ) with the dependent ordinal variables of mental wellbeing, personal 
wellbeing, social isolation, perceived attainment (undergraduate and postgraduate modelled separately), and perceptions of employment. Assumptions of proportional odds were checked using Brant's test ${ }^{38}$ which was met for all models described below. Unadjusted models with just PA level were performed, as well as four other adjusted models with the first (model 1) including age (years), sex ${ }^{1}$ ('female' $=0$, 'male' $=1$ ), ethnicity ${ }^{2}$ ('white' $=0$, 'non-white' $=1$ ), and whether a health problem/disability was present that limited daily activity ${ }^{3}$ ('no' $=0$, 'yes, limited a little' $=1$, 'yes, limited a lot' $=2$ ). The second (model 2) included daily sitting (minutes) additionally, the third (model 3) included additionally gym membership ('no' $=0$, 'yes' $=1$ ), sports membership ('no' = 0 , 'yes' = 1), and knowledge of PA guidelines ('no' $=0$, 'yes' $=1$ ), and the final fully adjusted model including additionally part time work ('no' $=0$, 'yes' $=1$ ). Study time per week ('fewer than 5 hours' $=0$, ' 5 10 hours' $=1$, ' $10-15$ hours' $=2$, ' $15-20$ hours' $=3$, '20-25 hours' $=4$, '25-30 hours' $=5$, ' $30+$ hours' $=6$ ) was also included in a final fully adjusted model but this was done separately as data was not available for this from the SASS. Separate models were also produced for employability outcomes as dependent variables adjusting for perceptions of whether physical activity/sport improved employability and whether they would refer to it in an interview. Models were produced hierarchically and model comparisons were examined using likelihood ratio tests. PA level was modelled as a first degree (linear) polynomial in each instance. Odds ratios (OR) with $95 \%$ confidence intervals (CI) were calculated. All analysis was performed using $\mathrm{R}$ (version 3.5.0; R Core Development Team, https://www.rproject.org/). An $\alpha$ of 0.05 was used to

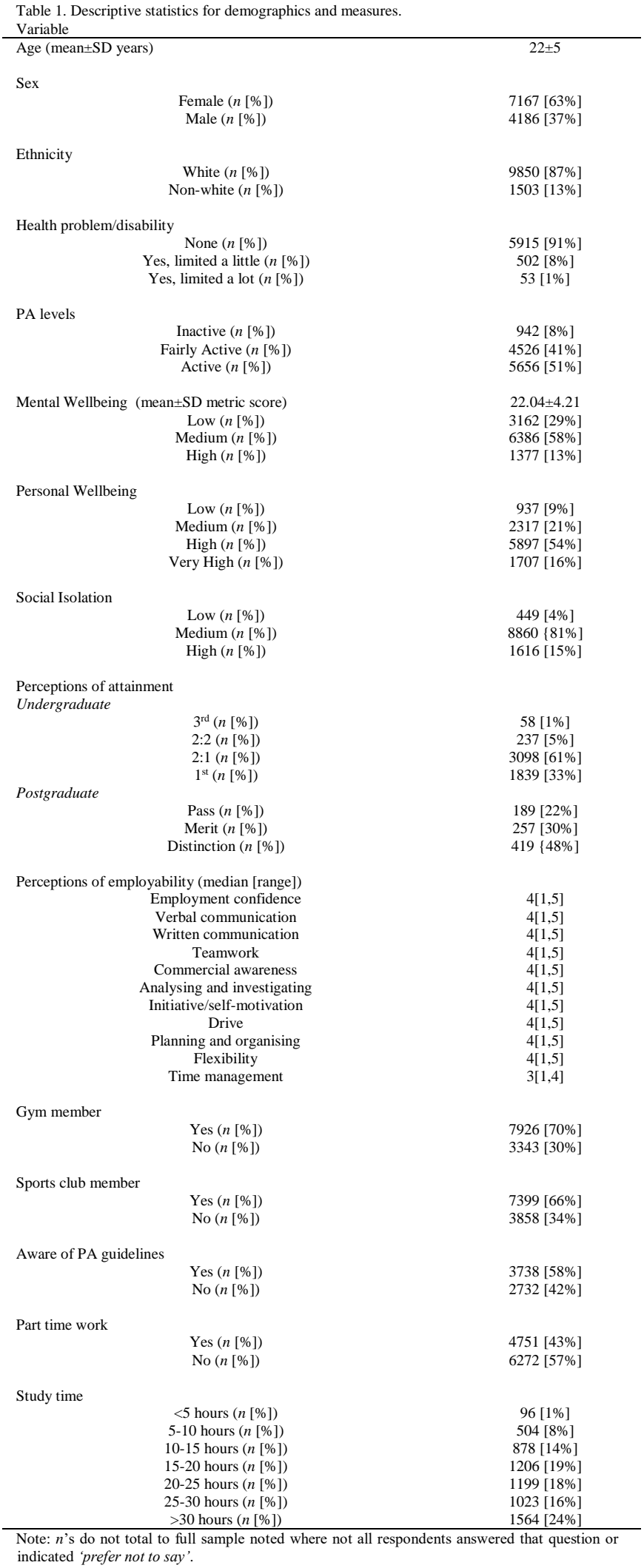

\footnotetext{
${ }^{1}$ Both the SASS and BASS utilized different options for this question. The SASS used 'female', 'male', and 'prefer not to say', while the BASS used 'cis Woman', 'cis Man', 'trans Woman', 'trans Man', 'in another way', and 'prefer not to say'. For this only 'female' and 'cis Woman' (both coded as 'female'), and 'male' and 'cis Man' (both
} coded as 'male) from the SSS and BASS were used respectively. Thus $n=148$ participant's data were excluded. 
Table 2. Summary of cumulative ordinal regression for independent variables predictive of mental wellbeing category (low, medium, high).

\begin{tabular}{|c|c|c|}
\hline \multirow[t]{2}{*}{ thents } & \multicolumn{2}{|c|}{ Odds ratios [95\%CIs] } \\
\hline & Unadjusted & $\begin{array}{l}\text { Fully } \\
\text { Adjusted }\end{array}$ \\
\hline PA level (linear) & $\begin{array}{c}1.66[1.51 \text { to } \\
1.83]\end{array}$ & $\begin{array}{c}1.48[1.28 \text { to } \\
1.72]\end{array}$ \\
\hline Age (years) & - & $\begin{array}{c}1.03 \text { [1.01 to } \\
1.04]\end{array}$ \\
\hline Sex & & \\
\hline Male & - & Reference \\
\hline Female & - & $\begin{array}{c}0.72[0.65 \text { to } \\
0.80]\end{array}$ \\
\hline Ethnicity & & \\
\hline Non-white & - & Reference \\
\hline White & - & $\begin{array}{c}0.83[0.72 \text { to } \\
0.95]\end{array}$ \\
\hline $\begin{array}{l}\text { Health } \\
\text { problem/Disability }\end{array}$ & & \\
\hline $\begin{array}{c}\text { No } \\
\text { Yes, limited a little }\end{array}$ & $\begin{array}{l}- \\
-\end{array}$ & $\begin{array}{c}\text { Reference } \\
0.48[0.40 \text { to } \\
0.57]\end{array}$ \\
\hline Yes, limited a lot & - & $\begin{array}{c}0.47[0.27 \text { to } \\
0.82]\end{array}$ \\
\hline Daily sitting (mins) & - & 1.00 \\
\hline Gym membership & & \\
\hline No & - & Reference \\
\hline Yes & - & $\begin{array}{c}1.11[1.00 \text { to } \\
1.24]\end{array}$ \\
\hline Sports membership & & \\
\hline No & - & Reference \\
\hline Yes & - & $\begin{array}{c}1.08[0.96 \text { to } \\
1.22]\end{array}$ \\
\hline $\begin{array}{l}\text { Knowledge of PA } \\
\text { guidelines }\end{array}$ & & \\
\hline No & - & Reference \\
\hline Yes & - & $\begin{array}{c}1.26[1.14 \text { to } \\
1.40]\end{array}$ \\
\hline Part time work & & \\
\hline No & - & Reference \\
\hline Yes & - & $\begin{array}{c}0.97[0.88 \text { to } \\
1.07]\end{array}$ \\
\hline
\end{tabular}

determine statistical significance for tests of assumptions and model fit, and results were considered as point estimates and precision of estimates (ORs [95\%CIs]) for the effects of PA level in both unadjusted and adjusted models.

\section{RESULTS}

The final data set analyzed included 11,462 participants. Table 1 reports descriptive statistics for demographics and measures.

\section{Mental Wellbeing}

When considering mental wellbeing category as the dependent variable, the unadjusted ordinal regression model with just PA level provided a significantly improved fit over the intercept only model according to the likelihood ratio test $\left(\chi^{2}=\right.$ 123.03, $\mathrm{df}=2, p<0.001)$. Addition of sex, ethnicity, and health problem/disability to the model provided a significantly improved fit over the unadjusted model $\left(\chi^{2}\right.$ $=140.1, \mathrm{df}=5, p<0.001)$. Addition of daily sitting time also resulted in a model which was significantly improved over the prior partially adjusted model $\left(\chi^{2}=23.218\right.$, df $=1, p<0.001)$. Addition of both gym membership and sports club membership also significantly improved model fit compared to the prior partially adjusted model $\left(\chi^{2}=27.383, \mathrm{df}=3, p<0.001\right)$. The final fully adjusted model including part time work did not improve fit compared to the prior model $\left(\chi^{2}=0.3654\right.$, df $=1, p<$ 0.999).

Though model fit was improved with the addition of certain parameters, the ORs for the effect of PA level upon mental wellbeing category were not substantially affected. Both partially and fully adjusted models compared with the initial unadjusted model all suggested that higher PA levels were associated with increased odds of being in a higher mental wellbeing category $(\mathrm{ORs}=1.48$ to 1.66$)$. The fully adjusted model with study time per week (using only BASS data) produced similar results $(\mathrm{OR}=1.47$ [1.27 to 1.70$])$. Table 2 shows ORs and 95\%CIs for the unadjusted and fully adjusted models.

\section{Personal Wellbeing}

When considering personal wellbeing scores categorized as ordinal variables for life satisfaction, worthwhileness, happiness, and anxiety, it was found that all respondents were similarly categorised across the questions. Thus personal wellbeing scores were simply considered as a single ordinal variable with a higher coded grouping indicating a better score for each question (Note: anxiety was negatively scored and so was coded with low scores indicating a more positive response).

When considering the personal wellbeing category as the dependent 
Table 3. Summary of cumulative ordinal regression for independent variables predictive of personal wellbeing category (Life satisfaction, worthwhileness, happiness - low, medium, high, very high; anxiety - high, medium, low, very low).

\begin{tabular}{|c|c|c|}
\hline & \multicolumn{2}{|c|}{ Odds ratios [95\%CIs] } \\
\hline & Unadjusted & Fully \\
\hline & & Adjusted \\
\hline \multirow[t]{2}{*}{ PA level (linear) } & $1.65[1.50$ to & $1.47[1.27$ to \\
\hline & $1.82]$ & 1.69] \\
\hline \multirow[t]{2}{*}{ Age (years) } & - & $1.01[1.00$ to \\
\hline & & $1.02]$ \\
\hline \multicolumn{3}{|l|}{ Sex } \\
\hline Male & - & Reference \\
\hline \multirow[t]{2}{*}{ Female } & - & $0.96[0.88$ to \\
\hline & & 1.07] \\
\hline \multicolumn{3}{|l|}{ Ethnicity } \\
\hline Non-white & - & Reference \\
\hline \multirow[t]{2}{*}{ White } & - & $1.00[0.88$ to \\
\hline \multirow{2}{*}{\multicolumn{3}{|c|}{$\begin{array}{l}\text { Health } \\
\text { problem/Disability }\end{array}$}} \\
\hline & & \\
\hline No & - & Reference \\
\hline \multirow[t]{2}{*}{ Yes, limited a little } & - & $0.45[0.37$ to \\
\hline & & $0.53]$ \\
\hline \multirow[t]{2}{*}{ Yes, limited a lot } & - & $0.35[0.20$ to \\
\hline & & $0.59]$ \\
\hline Daily sitting (mins) & - & 1.00 \\
\hline \multicolumn{3}{|l|}{ Gym membership } \\
\hline No & - & Reference \\
\hline \multirow[t]{2}{*}{ Yes } & - & $1.06[0.96$ to \\
\hline & & $1.18]$ \\
\hline \multicolumn{3}{|l|}{ Sports membership } \\
\hline & - & Reference \\
\hline \multirow[t]{2}{*}{ Yes } & - & $1.22[1.09$ to \\
\hline & & $1.36]$ \\
\hline \multirow{2}{*}{\multicolumn{3}{|c|}{$\begin{array}{l}\text { Knowledge of PA } \\
\text { guidelines }\end{array}$}} \\
\hline & & \\
\hline No & - & Reference \\
\hline \multirow[t]{2}{*}{ Yes } & - & $1.26[1.16$ to \\
\hline & & $1.41]$ \\
\hline \multicolumn{3}{|l|}{ Part time work } \\
\hline No & - & Reference \\
\hline Yes & - & $\begin{array}{c}0.93[0.84 \text { to } \\
1.02]\end{array}$ \\
\hline
\end{tabular}

variable, the unadjusted ordinal regression model with just PA level provided a significantly improved fit over the intercept only model according to the likelihood ratio test $\left(\chi^{2}=138.69, \mathrm{df}=2, p<0.001\right)$. Addition of sex, ethnicity, and health problem/disability to the model provided a significantly improved fit over the unadjusted model $\left(\chi^{2}=99.222, \mathrm{df}=5, p<\right.$ 0.001 ). Addition of daily sitting time also resulted in a model which was significantly improved over the prior partially adjusted model $\left(\chi^{2}=23.218, \mathrm{df}=1, p<0.001\right)$. Addition of both gym membership and sports club membership also significantly improved model fit compared to the prior partially adjusted model $\left(\chi^{2}=37.312, \mathrm{df}=\right.$ $3, p<0.001)$. The final fully adjusted model including part time work did not improve fit compared to the prior model $\left(\chi^{2}=2.496, \mathrm{df}\right.$ $=1, p=0.114$ ).

Though model fit was improved with the addition of certain parameters, the ORs for the effect of PA level upon personal wellbeing category were not substantially affected. Both partially and fully adjusted models compared with the initial unadjusted model all suggested that higher PA levels were associated with increased odds of being in a higher personal wellbeing category $(\mathrm{ORs}=1.47$ to 1.65$)$. The fully adjusted model with study time per week (using only BASS data) produced similar results $(\mathrm{OR}=1.43$ [1.24 to 1.65$]$ ). Table 3 shows ORs and 95\% CIs for the unadjusted and fully adjusted models.

\section{Social isolation}

When considering the social isolation category as the dependent variable, the unadjusted ordinal regression model with just PA level provided a significantly improved fit over the intercept only model according to the likelihood ratio test $\left(\chi^{2}=\right.$ 73.99 , $\mathrm{df}=2, p<0.001)$. Addition of sex, ethnicity, and health problem/disability to the model provided a significantly improved fit over the unadjusted model $\left(\chi^{2}=140.31\right.$, $\mathrm{df}=5, p<0.001)$. Addition of daily sitting time also resulted in a model which was significantly improved over the prior partially adjusted model $\left(\chi^{2}=14.482, \mathrm{df}=\right.$ $1, p<0.001)$. The addition of both gym membership and sports club membership also significantly improved model fit compared to the prior partially adjusted model $\left(\chi^{2}=40.243, \mathrm{df}=3, p<0.001\right)$. The final fully adjusted model including part time work did not improve fit compared to the prior model $\left(\chi^{2}=0.099\right.$, $\mathrm{df}=1, p=$ $0.753)$.

Though model fit was improved with the addition of certain parameters, the ORs for the effect of PA level upon social isolation category were not substantially affected. Both partially and fully adjusted models compared with the initial unadjusted model all suggested that higher 
Table 4. Summary of cumulative ordinal regression for independent variables predictive of social isolation category (low, medium, high).

\begin{tabular}{|c|c|c|}
\hline \multirow[t]{2}{*}{ (1) } & \multicolumn{2}{|c|}{ Odds ratios [95\%CIs] } \\
\hline & Unadjusted & $\begin{array}{c}\text { Fully } \\
\text { Adjusted }\end{array}$ \\
\hline PA level (linear) & $\begin{array}{l}0.60[0.54 \text { to } \\
0.68]\end{array}$ & $\begin{array}{c}0.75[0.63 \text { to } \\
0.90]\end{array}$ \\
\hline Age (years) & - & $\begin{array}{c}0.97[0.95 \text { to } \\
0.98]\end{array}$ \\
\hline Sex & & \\
\hline Male & - & Reference \\
\hline Female & - & $\begin{array}{c}1.33[1.16 \text { to } \\
1.52]\end{array}$ \\
\hline Ethnicity & & \\
\hline Non-white & - & Reference \\
\hline White & - & $\begin{array}{c}0.89[0.74 \text { to } \\
1.06]\end{array}$ \\
\hline $\begin{array}{l}\text { Health } \\
\text { problem/Disability }\end{array}$ & & \\
\hline $\begin{array}{c}\text { No } \\
\text { Yes, limited a little }\end{array}$ & $\begin{array}{l}- \\
-\end{array}$ & $\begin{array}{c}\text { Reference } \\
2.65[2.16 \text { to } \\
3.24]\end{array}$ \\
\hline Yes, limited a lot & - & $\begin{array}{c}4.66[2.67 \text { to } \\
8.13]\end{array}$ \\
\hline Daily sitting (mins) & - & 1.00 \\
\hline Gym membership & & \\
\hline $\begin{array}{l}\text { No } \\
\text { Yes }\end{array}$ & $\begin{array}{l}- \\
-\end{array}$ & $\begin{array}{c}\text { Reference } \\
0.86[0.75 \text { to } \\
0.99]\end{array}$ \\
\hline Sports membership & & \\
\hline No & - & Reference \\
\hline Yes & - & $\begin{array}{c}0.65[0.56 \text { to } \\
0.75]\end{array}$ \\
\hline $\begin{array}{l}\text { Knowledge of PA } \\
\text { guidelines }\end{array}$ & & \\
\hline No & - & Reference \\
\hline Yes & - & $\begin{array}{c}0.90[0.79 \text { to } \\
1.02]\end{array}$ \\
\hline Part time work & & \\
\hline No & - & Reference \\
\hline Yes & - & $\begin{array}{c}0.98[0.86 \text { to } \\
1.11]\end{array}$ \\
\hline
\end{tabular}

PA levels were associated with increased odds of being in a lower social isolation category $(\mathrm{ORs}=0.60$ to 0.75$)$. The fully adjusted model with study time per week (using only BASS data) produced similar results $(\mathrm{OR}=0.76[0.63$ to 0.90$])$. Table 4 shows ORs and 95\%CIs for the unadjusted and fully adjusted models.

\section{Perceived attainment}

When considering the perceived attainment of undergraduate students as the dependent variable, the unadjusted ordinal regression model with just PA level provided a significantly improved fit over the intercept only model according to the likelihood ratio test $\left(\chi^{2}=42.436, \mathrm{df}=2, p<\right.$ $0.001)$. Addition of sex, ethnicity, and health problem/disability to the model provided a significantly improved fit over the unadjusted model $\left(\chi^{2}=47.428, \mathrm{df}=5, p<\right.$ $0.001)$. Addition of daily sitting time to the model did not improve fit over the prior partially adjusted model $\left(\chi^{2}=0.0376, \mathrm{df}=\right.$ $1, p<0.8463)$. Addition of both gym membership and sports club membership also significantly improved model fit compared to the prior partially adjusted model $\left(\chi^{2}=12.025, \mathrm{df}=3, p=0.007\right)$. The final fully adjusted model including part time work did not improve fit compared to the prior model $\left(\chi^{2}=3.8181\right.$, df $=1, p=$ 0.0507).

Though model fit was improved with the addition of certain parameters, the ORs for the effect of PA level upon perceived attainment were not substantially affected. Both partially and fully adjusted models compared with the initial unadjusted model all suggested that higher PA levels were associated with increased odds of being in a higher of perceived attainment category (ORs $=1.64$ to 1.76$)$. The fully adjusted model with study time per week (using only BASS data) produced similar results $(\mathrm{OR}=1.67$ [1.31 to 2.13]). Table 5 shows ORs and 95\%CIs for the unadjusted and fully adjusted models.

When considering the perceived attainment of postgraduate students as the dependent variable, the unadjusted ordinal regression model with just PA level did not significantly improve fit over the intercept only model according to the likelihood ratio test $\left(\chi^{2}=2.2979, \mathrm{df}=2, p=0.317\right)$. None of the examined models provided significantly improved fit. ORs for the effect of PA level upon of perceived attainment of postgraduate students were not clearly suggestive of PA levels being predictive of perceived attainment in postgraduate students (ORs for unadjusted model $=1.13$ [0.71 to 1.78$]$ ).

\section{Perceived employability}

When considering the perception of employability success and skills as the dependent variable, the unadjusted ordinal regression model with just PA level provided a significantly improved fit over 
Table 5. Summary of cumulative ordinal regression for independent variables predictive of undergraduate student perceived attainment category $\left(3^{\text {rd }}, 2: 2,2: 1,1^{\text {st }}\right)$

\begin{tabular}{|c|c|c|}
\hline & \multicolumn{2}{|c|}{ Odds ratios [95\%CIs] } \\
\hline & Unadjusted & $\begin{array}{c}\text { Fully } \\
\text { Adjusted }\end{array}$ \\
\hline PA level (linear) & $\begin{array}{l}1.64[1.31 \text { to } \\
2.05]\end{array}$ & $\begin{array}{c}1.76[1.38 \text { to } \\
2.24]\end{array}$ \\
\hline Age (years) & - & $\begin{array}{c}1.00[0.98 \text { to } \\
1.02]\end{array}$ \\
\hline Sex & & \\
\hline Male & - & Reference \\
\hline Female & - & $\begin{array}{c}0.69[0.60 \text { to } \\
0.80]\end{array}$ \\
\hline Ethnicity & & \\
\hline Non-white & - & Reference \\
\hline White & - & $\begin{array}{c}0.67[0.54 \text { to } \\
0.82]\end{array}$ \\
\hline $\begin{array}{l}\text { Health } \\
\text { problem/Disability }\end{array}$ & & \\
\hline No & - & Reference \\
\hline Yes, limited a little & - & $\begin{array}{c}1.03[0.79 \text { to } \\
1.35]\end{array}$ \\
\hline Yes, limited a lot & - & $\begin{array}{c}1.87[0.86 \text { to } \\
4.08]\end{array}$ \\
\hline Daily sitting (mins) & - & 1.00 \\
\hline Gym membership & & \\
\hline No & - & Reference \\
\hline Yes & - & $\begin{array}{c}1.11[0.94 \text { to } \\
1.30]\end{array}$ \\
\hline Sports membership & & \\
\hline No & - & Reference \\
\hline Yes & - & $\begin{array}{c}0.76[0.64 \text { to } \\
0.90]\end{array}$ \\
\hline $\begin{array}{l}\text { Knowledge of PA } \\
\text { guidelines }\end{array}$ & & \\
\hline No & - & Reference \\
\hline Yes & - & $\begin{array}{c}1.06[0.92 \text { to } \\
1.30]\end{array}$ \\
\hline Part time work & & \\
\hline No & - & Reference \\
\hline Yes & - & $\begin{array}{c}0.87[0.75 \text { to } \\
1.00]\end{array}$ \\
\hline
\end{tabular}

the intercept only model according to the likelihood ratio test for most variables $\left(\chi^{2}=\right.$ 9.6131 to 94.004 , $\mathrm{df}=2, p=0.008$ to $<$ 0.001 ) with the exception of written communication $\left(\chi^{2}=0.4628, \mathrm{df}=2, p=\right.$ 0.7934). Addition of sex, ethnicity, and health problem/disability to the model provided a significantly improved fit over the unadjusted model for all variables $\left(\chi^{2}=\right.$ 26.865 to 230.31 , df $=5, p<0.001)$. Addition of daily sitting time to the model significantly improved fit over the prior partially adjusted model $\left(\chi^{2}=3.8579\right.$ to 22.662 , $\mathrm{df}=1, p=0.0495$ to $<0.001)$ with the exception of written communication $\left(\chi^{2}\right.$ $=0.4586, \mathrm{df}=1, p=0.4983)$ and flexibility $\left(\chi^{2}=2.2493\right.$, df $\left.=2, p=0.1337\right)$. Addition of both gym membership and sports club membership also significantly improved model fit compared to the prior partially adjusted model for all variables $\left(\chi^{2}=13.96\right.$ to $95.331, \mathrm{df}=3, p<0.001)$. The final fully adjusted model including part time work improved fit compared to the prior model for all variables $\left(\chi^{2}=5.2382\right.$ to $42.872, \mathrm{df}=$ $1, p=0.0221$ to $<0.001)$ with the exception of employment confidence $\left(\chi^{2}=0.008, \mathrm{df}=\right.$ $1, p=0.9269)$ and analysing and investigating $\left(\chi^{2}=0.1263\right.$, df $=1, p=$ 0.7223).

Though model fit was generally improved with the addition of certain parameters, the ORs for the effect of PA level upon perception of employability success and skills were not substantially affected. Both partially and fully adjusted models compared with the initial unadjusted model all suggested that higher PA levels were associated with increased odds of being in a higher perception of employability success and skills category with the lowest ORs being for written communication (employment confidence, ORs $=1.33$ to 1.27 ; verbal communication, ORs $=1.23$ to 1.12 ; written communication, $\mathrm{ORs}=1.04$ to 1.18 ; teamwork, $\mathrm{ORs}=1.53$ to 1.27 ; commercial awareness, $\mathrm{ORs}=1.22$ to 1.15 ; analysing and investigating, $\mathrm{ORs}=1.43$ to 1.58 ; initiative/self-motivation, $\mathrm{ORs}=1.54$ to 1.51 ; drive, ORs $=1.62$ to 1.57 ; planning and organising, ORs $=1.35$ to 1.38; flexibility, ORs $=1.29$ to 1.25 ; time management, OR = 1.39). The fully adjusted model with study time per week (using only BASS data) produced similar results though verbal communication and time management had the lowest ORs with 95\% CIs crossing 1.00 (employment confidence, $\mathrm{OR}=1.20$ [1.05 to 1.38]; verbal communication, $\mathrm{OR}=1.09[0.95$ to 1.26]; written communication, $\mathrm{OR}=1.17$ [1.02 to 1.34 ]; teamwork, $\mathrm{OR}=1.25$ [1.09 to 1.44$]$; commercial awareness, $\mathrm{OR}=1.15$ [1.00 to 1.32 ]; analysing and investigating, $\mathrm{OR}=1.51[1.31$ to 1.74$]$; initiative/selfmotivation, $\mathrm{OR}=1.44$ [1.25 to 1.66]; drive, $\mathrm{OR}=1.49$ [1.30 to 1.71$]$; planning and organising, $\mathrm{OR}=1.33$ [1.15 to 1.53]; flexibility, $\mathrm{OR}=1.15$ [1.00 to 1.32 ]; time 
Table 6. Summary of cumulative ordinal regression for independent variables predictive of perception of employability success and skills $(1$ to 5

\begin{tabular}{|c|c|c|c|c|c|c|c|c|c|c|c|c|c|c|c|c|c|c|c|c|c|c|}
\hline & \multicolumn{2}{|c|}{ Employment confidence } & \multicolumn{2}{|c|}{ Verbal communication } & \multicolumn{2}{|c|}{ Written communication } & \multicolumn{2}{|c|}{ Teamwork* } & \multicolumn{2}{|c|}{ Commercial awareness } & \multicolumn{2}{|c|}{$\begin{array}{c}\text { Odds ratios }[95 \% \mathrm{Cls}] \\
\text { Analysing and } \\
\text { investigating* }\end{array}$} & \multicolumn{2}{|c|}{ Initiative/self-motivation } & \multicolumn{2}{|c|}{ Drive } & \multicolumn{2}{|c|}{ Planning and organizing } & \multicolumn{2}{|c|}{ Flexibility } & \multicolumn{2}{|c|}{ Time management } \\
\hline & Unadjuste & $\begin{array}{c}\text { Fully } \\
\text { Adusted }\end{array}$ & Unadjuste & $\begin{array}{c}\text { Fully } \\
\text { Adiusted }\end{array}$ & Unadjuste & $\begin{array}{l}\text { Fully } \\
\text { full }\end{array}$ & Unadjuste & $\begin{array}{l}\text { Fully } \\
\text { Fuly }\end{array}$ & Unadjuste & Fully & $\begin{array}{l}\text { investi } \\
\text { Unadjuste }\end{array}$ & $\begin{array}{l}\text { nge } \\
\text { Fully } \\
\text { tdivsted }\end{array}$ & Unadjuste & Fully & Unadjuste & $\begin{array}{l}\text { Fully } \\
\text { Adivted }\end{array}$ & Unadjuste & Fully & Unadjuste & Fully & Unadjuste & Fully \\
\hline PA level (linear) & $\begin{array}{c}1.33[1.17 \\
\text { to } 1.51]\end{array}$ & $\begin{array}{l}1.27 \\
{[1.11 \text { to }}\end{array}$ & $\begin{array}{c}1.23[1.08 \\
\text { to } 1.40]\end{array}$ & $\begin{array}{l}1.12 \\
{[0.98 \text { to }}\end{array}$ & $\begin{array}{c}1.04[0.92 \\
\text { to } 1.18]\end{array}$ & $\begin{array}{l}1.18 \\
{[1.03 \text { to }} \\
\end{array}$ & $\begin{array}{c}1.53[1.34 \\
\text { to } 1.74]\end{array}$ & $\begin{array}{l}1.1 .7 \\
{[1.11 \text { to }}\end{array}$ & $\begin{array}{c}1.22[1.07 \\
\text { to } 1.38]\end{array}$ & $\begin{array}{l}1.15 \\
{[1.00 \text { to }} \\
\end{array}$ & $\begin{array}{c}1.43[1.26 \\
\text { to } 1.63]\end{array}$ & $\begin{array}{l}1.58 \\
{[1.38 \text { to }}\end{array}$ & $\begin{array}{c}1.54[1.35 \\
\text { to } 1.76]\end{array}$ & $\begin{array}{l}1.151 \\
{[1.31 \text { to }}\end{array}$ & $\begin{array}{l}1.62[1.42 \\
\text { to } 1.85]\end{array}$ & $\begin{array}{l}1.57 \\
{[1.37 \text { to }}\end{array}$ & $\begin{array}{l}1.35[1.19 \\
\text { to } 1.55]\end{array}$ & $\begin{array}{l}\text { Aqusted } \\
1.28 \\
{[1.20 \text { to }}\end{array}$ & $\begin{array}{l}1.2911 .13 \\
\text { to } 1.47]\end{array}$ & $\begin{array}{l}\text { Aquster } \\
1.25 \\
{[1.08 \text { to }}\end{array}$ & $\begin{array}{l}1.39[1.23 \\
\text { to } 1.58]\end{array}$ & $\begin{array}{l}1.39 \\
{[1.22 \text { to }}\end{array}$ \\
\hline Age (years) & & $\begin{array}{c}1.46] \\
1.06 \\
{[1.05} \\
1.08]\end{array}$ & & $\begin{array}{c}1.29] \\
1.04 \\
{[1.0310} \\
1.05]\end{array}$ & & $\begin{array}{l}1.36] \\
1.03 \\
{[1.0210} \\
1.04]\end{array}$ & & $\begin{array}{c}1.46] \\
1.02 \\
{[1.0110} \\
1.03]\end{array}$ & & $\begin{array}{l}1.31] \\
1.03 \\
{[1.02} \\
\text { to1.04] }\end{array}$ & & $\begin{array}{c}1.82] \\
1.04 \\
{[1.03 \text { to }} \\
1.06]\end{array}$ & & $\begin{array}{c}1.74] \\
1.05 \\
{[1.03 \text { to }} \\
1.06]\end{array}$ & & $\begin{array}{c}1.81] \\
1.02 \\
{[1.0110} \\
1.03]\end{array}$ & & $\begin{array}{l}1.59] \\
1.03 \\
{[1.0210} \\
1.04]\end{array}$ & & $\begin{array}{c}1.43] \\
1.03 \\
{[1.0210} \\
1.04]\end{array}$ & & $\begin{array}{c}1.591 \\
1.02 \\
{\left[\begin{array}{c}1.01 \\
1.03] \\
1.03]\end{array}\right.}\end{array}$ \\
\hline Sex Male & . & Referenc & . & Referenc & . & Referenc & . & Referenc & & Referenc & . & Referenc & . & Referenc & . & Referenc & - & Referenc & . & Referenc & . & Referenc \\
\hline Female & - & $\begin{array}{c}e \\
0.69 \\
{[0.63 \text { to }} \\
0.75]\end{array}$ & . & $\begin{array}{c}\mathrm{e} \\
0.86 \\
{[0.7810} \\
0.94]\end{array}$ & . & $\begin{array}{c}\mathrm{e} \\
1.43 \\
{[1.300} \\
1.58]\end{array}$ & - & $\begin{array}{c}\mathrm{e} \\
1.00 \\
{[0.91 \text { to }} \\
1.10]\end{array}$ & & $\begin{array}{c}\mathrm{e} \\
0.62 \\
{[0.57 \mathrm{to}} \\
0.68]\end{array}$ & . & $\begin{array}{c}\mathrm{e} \\
0.76 \\
{[0.76 \text { to }} \\
0.84]\end{array}$ & . & $\begin{array}{c}\mathrm{e} \\
1.20 \\
{[1.0990} \\
1.33]\end{array}$ & . & $\begin{array}{c}\mathrm{e} \\
1.33 \\
{[1.21 \text { to }} \\
1.47]\end{array}$ & . & $\begin{array}{c}e \\
1.87 \\
{[1.70 \text { to }} \\
2.06]\end{array}$ & . & $\begin{array}{c}\mathrm{e} \\
0.94 \\
{[0.85 \text { to }} \\
1.03]\end{array}$ & . & $\begin{array}{c}\mathrm{e} \\
1.61 \\
{\left[\begin{array}{c}1.47 \mathrm{to} \\
1.77]\end{array}\right.}\end{array}$ \\
\hline $\begin{array}{l}\text { Ethnicity } \\
\text { Non-white }\end{array}$ & & Referenc & & Referenc & & Referenc & & Referenc & & Referenc & & Referenc & & Referenc & & Referenc & & Referenc & & Referenc & & Referenc \\
\hline White & & $\begin{array}{c}e \\
1.06 \\
{[0.93 \text { to }} \\
1.21]\end{array}$ & . & $\begin{array}{c}e \\
1.31 \\
{[1.1550} \\
1.49]\end{array}$ & . & $\begin{array}{c}\mathrm{e} \\
1.05 \\
{[0.92 \mathrm{to}} \\
1.20]\end{array}$ & & $\begin{array}{c}e \\
1.16 \\
{[1.016} \\
1.33]\end{array}$ & . & $\begin{array}{c}e \\
1.02 \\
{[0.900} \\
1.16]\end{array}$ & & $\begin{array}{c}e \\
1.06 \\
{[0.93 \text { to }} \\
1.21]\end{array}$ & - & $\begin{array}{c}\mathrm{e} \\
1.00 \\
{[0.87 \text { to }} \\
1.14]\end{array}$ & . & $\begin{array}{c}e \\
1.18 \\
{[1.0310} \\
1.34]\end{array}$ & . & $\begin{array}{c}e \\
1.23 \\
{[1.088} \\
1.41]\end{array}$ & . & $\begin{array}{c}\mathrm{e} \\
0.88 \\
{[0.77 \mathrm{to}} \\
1.01]\end{array}$ & . & $\begin{array}{c}\mathrm{e} \\
1.24 \\
{\left[\begin{array}{c}1.29 \\
1.42 \\
1.42]\end{array}\right.}\end{array}$ \\
\hline \multicolumn{23}{|l|}{$\begin{array}{l}\text { Health } \\
\text { problem/Disabilit }\end{array}$} \\
\hline No & - & Referenc & - & Referenc & - & Referenc & . & Referenc & & Referenc & - & Referenc & - & Referenc & - & Referenc & - & Referenc & - & Referenc & - & Referenc \\
\hline $\begin{array}{l}\text { Yes, limited a } \\
\text { little }\end{array}$ & . & $\begin{array}{c}\mathrm{e} \\
0.81 \\
{[0.68 \text { to }}\end{array}$ & & $\begin{array}{c}\mathrm{e} \\
0.88 \\
{[0.74 \text { to }}\end{array}$ & & $\begin{array}{c}\mathrm{e} \\
0.89 \\
{[0.75 \text { to }}\end{array}$ & . & $\begin{array}{c}\mathrm{e} \\
0.76 \\
{[0.64 \mathrm{to}}\end{array}$ & & $\begin{array}{c}\mathrm{e} \\
1.05 \\
{\left[0.89 t^{\circ}\right.}\end{array}$ & . & $\begin{array}{c}\mathrm{e} \\
1.10 \\
{[0.93 \text { to }}\end{array}$ & & $\begin{array}{c}\mathrm{e} \\
0.83 \\
0.70 \text { to }\end{array}$ & . & $\begin{array}{c}\mathrm{e} \\
0.93 \\
{[0.79 \mathrm{to}}\end{array}$ & . & $\begin{array}{c}\mathrm{e} \\
0.81 \\
{[0.68 \mathrm{to}}\end{array}$ & & $\begin{array}{c}\mathrm{e} \\
0.73 \\
{[0.62 \text { to }}\end{array}$ & & $\begin{array}{c}\mathrm{e} \\
0.82 \\
{[0.70 \text { to }}\end{array}$ \\
\hline \multirow{3}{*}{ Yes, limited a lot } & & 0.967 & & $\begin{array}{l}1.040 \\
1.38\end{array}$ & & 1.066 & & 0.901 & & $\begin{array}{l}1.25 \\
1.20\end{array}$ & & $\begin{array}{l}1.320 \\
1.35\end{array}$ & & 0.999 & & 1.111 & & 0.966 & & 0.871 & & $\begin{array}{l}0.981 \\
0.97\end{array}$ \\
\hline & - & $\begin{array}{l}0.67 \\
{[0.41 \text { to }}\end{array}$ & - & 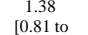 & - & $\begin{array}{l}0.81 \\
{[0.49 \text { to }}\end{array}$ & - & $\begin{array}{l}0.79 \\
{[0.47 \text { to }}\end{array}$ & & $\begin{array}{l}1.30 \\
1079 \text { to }\end{array}$ & - & $\begin{array}{l}1.35 \\
{[081 \text { to }}\end{array}$ & - & $\begin{array}{l}0.72 \\
0.02 \text { to }\end{array}$ & - & $\begin{array}{l}0.57 \\
0.34\end{array}$ & - & $\begin{array}{l}0.66 \\
{[0.39 \text { to }}\end{array}$ & - & $\begin{array}{l}0.41 \\
{[024 t 0}\end{array}$ & - & 0.57 \\
\hline & & $1.11]$ & & $2.36]$ & & $1.35]$ & & $\begin{array}{l}0.4 .34] \\
1.34]\end{array}$ & & $2.15]$ & & $2.25]$ & & $1.23]$ & & to0.94] & & $1.12]$ & & [0.70] & & $0.96]$ \\
\hline $\begin{array}{l}\begin{array}{l}\text { Daily } \\
\text { (mins) }\end{array} \\
\text { sitting }\end{array}$ & & 1.00 & - & 1.00 & - & 1.00 & & & - & 1.00 & & & - & 1.00 & - & 1.00 & - & 1.00 & - & 1.00 & - & 1.00 \\
\hline $\begin{array}{l}\text { Gym membership } \\
\text { No }\end{array}$ & & Referenc & & Reference & & Referenc & & Referenc & & Referenc & & Reference & & Referenc & & Referenc & & Reference & & Reference & & Referenc \\
\hline Yes & & $\begin{array}{c}\mathrm{e} \\
1.17 \\
{[1.0550} \\
1.29]\end{array}$ & - & $\begin{array}{c}\mathrm{e} \\
1.17 \\
{[1.05 \text { to }} \\
1.29]\end{array}$ & - & $\begin{array}{c}\mathrm{e} \\
1.00 \\
{[0.90 \mathrm{to}} \\
1.10]\end{array}$ & & $\begin{array}{c}\mathrm{e} \\
1.25 \\
{[1.1 .13 \mathrm{to}} \\
1.39]\end{array}$ & - & $\begin{array}{c}\mathrm{e} \\
1.16 \\
{[1.055} \\
1.29]\end{array}$ & & $\begin{array}{c}\mathrm{e} \\
1.01 \\
{[0.91 \text { to }} \\
1.12]\end{array}$ & - & $\begin{array}{c}\mathrm{e} \\
1.25 \\
{[1.13 \text { to }} \\
1.39]\end{array}$ & - & $\begin{array}{c}e \\
1.27 \\
{[1.15 \text { to }} \\
1.41]\end{array}$ & - & $\begin{array}{c}\mathrm{e} \\
1.19 \\
{[1.077} \\
1.32]\end{array}$ & - & $\begin{array}{c}\mathrm{e} \\
1.04 \\
{[0.9440} \\
1.15]\end{array}$ & - & $\begin{array}{c}\mathrm{e} \\
1.18 \\
{[1.1 .06 \text { to }} \\
1.30]\end{array}$ \\
\hline \multicolumn{23}{|l|}{$\begin{array}{l}\text { Sports } \\
\text { membership }\end{array}$} \\
\hline & - & Referenc & & Referenc & & Referenc & - & Referenc & & Referenc & - & Referenc & & Referenc & - & Referenc & & Referenc & & Referenc & & Referenc \\
\hline Yes & & $\begin{array}{c}c \\
1.00 \\
{[0.90 \text { to }} \\
1.12]\end{array}$ & & $\begin{array}{c}c \\
1.16 \\
{[1.04 t 0} \\
1.30]\end{array}$ & & $\begin{array}{c}0.79 \\
0.79 \\
{[0.71 \text { to }} \\
0.88]\end{array}$ & & $\begin{array}{c}1.53 \\
{[1.37 \text { to }} \\
1.71]\end{array}$ & & $\begin{array}{c}1.0 \\
1.00 \\
{[0.90 \text { to }} \\
1.11]\end{array}$ & & $\begin{array}{c}0.79 \\
{[0.70 \text { to }} \\
0.88]\end{array}$ & & $\begin{array}{c}c \\
1.05 \\
{[0.94 \text { to }} \\
1.17]\end{array}$ & & $\begin{array}{c}c \\
1.02 \\
{[0.91 \text { to }} \\
1.114]\end{array}$ & & $\begin{array}{c}0.94 \\
0.845 \\
{[0.05]} \\
1.05]\end{array}$ & & $\begin{array}{c}c \\
1.07 \\
{[0.96 \text { to }} \\
1.20]\end{array}$ & & $\begin{array}{c}0.92 \\
{[0.82 \text { to }} \\
1.02]\end{array}$ \\
\hline \multicolumn{23}{|l|}{$\begin{array}{l}\text { Knowledge of PA } \\
\text { guidelines }\end{array}$} \\
\hline No & & Referenc & - & Referenc & - & Referenc & & Referenc & - & Referenc & & Referenc & - & Referenc & & Referenc & - & Referenc & - & Referenc & & Referenc \\
\hline Yes & & $\begin{array}{c}\mathrm{e} \\
\begin{array}{c}1.22 \\
{[1.21} \\
1.45] \\
1.45]\end{array}\end{array}$ & & $\begin{array}{c}\mathrm{e} \\
1.18 \\
{[1.080} \\
1.30]\end{array}$ & & $\begin{array}{c}e \\
1.21 \\
{[1.1010} \\
1.32]\end{array}$ & & $\begin{array}{c}\mathrm{e} \\
1.22 \\
{[1.1110} \\
1.35]\end{array}$ & & $\begin{array}{c}\mathrm{e} \\
1.19 \\
{[1.080} \\
1.30]\end{array}$ & & $\begin{array}{c}1.07 \\
{[0.970} \\
1.17]\end{array}$ & & $\begin{array}{c}c .36 \\
{[1.240} \\
1.50] \\
1.50]\end{array}$ & & $\begin{array}{c}\mathrm{e} \\
\begin{array}{c}1.77 \\
{[1.240} \\
1.50]\end{array}\end{array}$ & & $\begin{array}{c}\mathrm{e} \\
\begin{array}{c}1.16 \\
{[1.06 \mathrm{to}} \\
1.277\end{array}\end{array}$ & & $\begin{array}{c}\mathrm{e} \\
1.16 \\
{[1.06 \mathrm{0}} \\
1.27] \\
\end{array}$ & & $\begin{array}{c}e \\
1.34 \\
{[1.22 \text { to }} \\
1 . .77]\end{array}$ \\
\hline $\begin{array}{l}\text { Part time work } \\
\text { No }\end{array}$ & - & Referenc & - & Referenc & - & Referenc & - & Referenc & & Referenc & - & Referenc & - & Referenc & - & Referenc & - & Referenc & - & Referenc & - & Referenc \\
\hline Yes & - & $\begin{array}{c}\mathrm{e} \\
1.00 \\
{[0.92 \text { to }} \\
1100\end{array}$ & - & $\begin{array}{c}e \\
1.34 \\
{[1.2220} \\
1.477\end{array}$ & . & $\begin{array}{c}\mathrm{e} \\
1.11 \\
{[1.0620} \\
1.22\end{array}$ & . & $\begin{array}{c}\mathrm{e} \\
1.12 \\
{[1.2010} \\
1.45\end{array}$ & & $\begin{array}{c}\mathrm{e} \\
1.29 \\
{[1.18 \mathrm{18}} \\
1.422\end{array}$ & . & $\begin{array}{c}\mathrm{e} \\
1.02 \\
{[0.93 \text { to }} \\
1.12]\end{array}$ & . & $\begin{array}{c}\mathrm{e} \\
1.23 \\
{[1.12120} \\
1.350\end{array}$ & . & $\begin{array}{c}\mathrm{e} \\
1.37 \\
{[1.250} \\
150\end{array}$ & . & $\begin{array}{c}e \\
1.26 \\
{[1.155} \\
1388\end{array}$ & . & 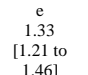 & . & $\begin{array}{c}\mathrm{e} \\
1.17 \\
{[1.07 \text { to }} \\
1.28\end{array}$ \\
\hline
\end{tabular}


management, $\mathrm{OR}=1.09$ [0.95 to 1.26$]$ ). Table 6 shows ORs and 95\%CIs for the unadjusted and fully adjusted models. The separate model examining the effect of PA level on perception of employability success and skills adjusting for perceptions of whether PA or exercise/sport improves employability, and whether the respondent would refer to PA or exercise/sport when applying for jobs again showed largely similar ORs (employment confidence, OR $=1.20[1.05$ to 1.38$] ;$ verbal communication, $\mathrm{OR}=1.12$ [0.98 to 1.29$]$; written communication, $\mathrm{OR}=1.06[0.92$ to 1.20]; teamwork, $\mathrm{OR}=1.23$ [1.07 to 1.41$]$; commercial awareness, $\mathrm{OR}=1.14$ [1.00 to 1.30]; analysing and investigating, $\mathrm{OR}=$ $1.48 \quad[1.29$ to 1.69$]$; initiative/selfmotivation, $\mathrm{OR}=1.40$ [1.23 to 1.60]; drive, $\mathrm{OR}=1.46$ [1.28 to 1.67$]$; planning and organising, $\mathrm{OR}=1.27$ [1.11 to 1.46$]$; flexibility, $\mathrm{OR}=1.18$ [1.03 to 1.35$]$; time management, 1.29 [1.13 to 1.47$]$ ).

\section{DISCUSSION}

This study reports a pooled secondary analysis of data from the SASS and BASS. The results suggest that students across the UK tend to be less likely to meet recommended PA levels $(51 \%)$ when compared to individuals their age, as shown in recent data from both England and Scotland. The most recent findings from Sport England's Active Lives survey reports that $76 \%$ of $16-24$ year olds meet current CMO PA recommendations ${ }^{27}$, and findings from the Scottish Health Survey reports that $78 \%$ of $16-24$ years olds meet current CMO PA recommendations ${ }^{39}$. Further, data from the SASSI reported that $64 \%$ of students in Ireland were meeting CMO PA recommendations which Murphy et al. ${ }^{25}$ noted is higher than comparable population data for 16-24 year olds in Ireland $^{40}$, the opposite to findings in this study. Despite the relatively low PA participation, analysis revealed that students who were more physically active tended to be $48 \%$ more likely to have higher mental wellbeing (fully adjusted model OR
$=1.48$ [1.28 to 1.72$]) ; 47 \%$ more likely to have higher personal wellbeing (fully adjusted model OR $=1.47$ [1.27 to 1.69 ]) and $25 \%$ less likely to feel socially isolated (fully adjusted model OR $=0.75$ [0.63 to 0.90]). Additionally, more physically active undergraduate students were $76 \%$ more likely to perceive their attainment to be higher, $27 \%$ more likely to have higher confidence in their ability to obtain employment upon graduation (fully adjusted model OR $=1.27$ [1.17 to 1.51$]$ ), and $12-58 \%$ more likely to have higher perceptions of a range of employability skills (See Table 6).

Mental wellbeing in this particular population is crucial as this group of young adults are exposed to a number of stressors that can negatively impact mental wellbeing ${ }^{12}$. These stressors include changes in residence, increases in responsibility, peer pressure, and the issues that arise with balancing academic classes, managing coursework and part time employment $^{41,42}$. Similar to the current study that identified $29 \%$ of the sample were categorized as low mental wellbeing, the SASSI revealed that $22.7 \%$ of the students were categorized as having "probable mental health problems" 25. Furthermore, Murphy et al. ${ }^{25}$ stated that those students meeting the PA guidelines were $55 \%$ more likely to report better mental health than those classified as inactive $(\mathrm{OR}=1.55$ [1.25 to 1.92$])$ comparable to the $48 \%$ of the current investigation. Several other studies have also highlighted the association between PA levels and aspects of mental health and wellbeing in students ${ }^{3,8,13}$. It has been argued that, considering the positive effect that PA can have on mental health, there is a need to move towards the implementation of initiatives to increase PA levels ${ }^{43}$. Indeed, PA interventions aimed at university students have been shown to improve perceived stress ${ }^{44}$ and results from the present analysis showing positive associations between PA and mental wellbeing provide support for the 
importance of promoting and facilitating PA in university settings.

The present study also included the examination of the association between PA levels and personal wellbeing in light of evidence which suggests perception of overall quality of life is influenced by $\mathrm{PA}^{45}$. The results show only $9 \%$ of the sample had a low personal wellbeing rating but a positive association between increased PA levels and greater personal wellbeing. Murphy and colleagues ${ }^{25}$ from the SASSI reported that, compared with students who did not meet the PA guidelines, students who met the PA guidelines were 2.2 times more likely to report feeling happy, and those who were moderately active were 1.46 times more likely to report feelings of happiness. In the present study we found a similar association between greater PA and happiness, in addition to other elements of personal wellbeing, with more active students $47 \%$ more likely to report better personal wellbeing. Other prior work has shown greater quality of life in students who meet PA recommendations mediated by self-esteem and positive affect ${ }^{12}$. Further, positive attitudes towards sport may be associated with self-esteem and life satisfaction ${ }^{46}$. Indeed, within the adjusted models in the present study, membership of a sports club influenced personal wellbeing and social isolation.

Alongside the increased independence with transitioning to higher education can be an accompanying increased perception of social isolation and loneliness for many students ${ }^{47}$. In fact, $15 \%$ of the sample from the present study reported high social isolation. The present study also found that students who were more physically active were $25 \%$ less likely to report high social isolation. Few studies have examined the impact of engaging in PA on social isolation levels, however research has found links between PA, socialization and mental health. Research aimed at investigating the association between vigorous PA and mental health, perceived stress, and socializing reported that socializing partially mediated the relationship between vigorous $\mathrm{PA}$ and mental health/perceived stress $^{8}$. This suggests that increased socialization may be the reason behind the positive associations between mental health and personal wellbeing with PA levels. In fact, a systematic review of 30 studies suggested that sport participation may positively impact upon social outcomes for children and adolescents ${ }^{48}$, although more research is needed to ascertain the causal relationships between these factors.

As noted, there is a growing literature suggesting a link between PA, executive function, and academic attainment in adolescents ${ }^{20}$. Though there is a lack of data examining university students, there is plausibility to a link between the two ${ }^{22}$, especially considering the link between PA and health and the suggestion that healthier students are better able to learn ${ }^{49}$. The present study appears to be the first to examine the potential link between PA levels and academic attainment in university level students. It should be noted that in the present survey students were asked to provide their perceptions of their attainment as it was not possible to obtain records of their actual grades. However, the present findings implied that undergraduate students who were more physically active were $75 \%$ more likely to perceive their academic attainment to be higher. For postgraduate students there was little association, although the reason for this is not clear from the present data. It has been suggested that stress levels are similar between undergraduate and postgraduate students, yet postgraduate students typically have greater social support $^{50}$ which may attenuate the potentially positive relationship between PA and attainment.

The potential positive impact of PA levels upon perceived attainment may in turn result in improved graduate employment and longer-term employability $^{21}$. Indeed, the present study found that students who were more active 
were $27 \%$ more likely to report higher confidence that they would be employed upon graduation. Further, across a range of employability skills students who were more active perceived themselves to be 12$58 \%$ better. The weakest effects were seen for commercial awareness and written communication, seemingly understandable as these are not generally skills involved during engagement in PA. Some of the additional factors examined in the adjusted models were found to potentially moderate some of the skills (see Table 6). For example, those who were members of a sports club were $53 \%$ more likely to rate themselves higher for teamwork. As mentioned, though data is sparse regarding the relationship between sport and attainment or employability, there is some evidence that sport may positively impact upon graduate employability ${ }^{21}$ and this would tend to support that perspective.

The limitations of the present study should be noted. Primarily, the survey conducted was cross-sectional in nature rendering it difficult to conclusively draw causal inference from the data. It might also be considered that the directionality of associations may imply that having better mental health, personal wellbeing, lower social isolation, and greater perception of attainment and employability may increase the likelihood of participating in PA. Selfreport was used for all outcomes, and in particular PA levels were assessed using a modified single-item minutes based activity question ${ }^{26}$ and as noted this is similar to that used in the Active Lives survey from Sport England ${ }^{27}$. Recent work has suggested that compared with longer PA questionnaires (i.e. the International Physical Activity Questionnaire-Short Form), single-item based measures may offer poorer agreement with objective measures using accelerometers in university students ${ }^{51}$. However, here the use of the single-item measure in the SASS and BASS was considered most appropriate given the length of the survey when combined with the other outcomes examined. Further to this, though most outcomes were measured using existing tools and questions (SWEMWBS, ONSPWB4, PROMIS-SI4a), perceptions of attainment, and employability confidence and skills were not, rendering their validity less clear. Lastly, the exact response rates, including number of students at institutions surveyed at the time of the survey, the proportion of those who clicked the link to the survey, and the proportion of those that completed it is not clear. However, research has suggested that estimates of effects are similar across a range of response rates for college survey data $^{52}$. Nonetheless, though the survey could be considered representative of UK based university students, it should not be neglected that the interests of participants have been shown to influence their likelihood of responding and so it could be that the respondent sample examined here are not necessarily wholly representative of the university student population as a whole ${ }^{53}$.

\section{CONCLUSIONS}

This combined analysis of the SASS and BASS is the largest representative examination of PA levels in UK based university students. This data provides a comparator against other populations and for examination of changes over time in the student population. At present, data suggests that UK university students are insufficiently active compared with the general population of 16-24 year olds. PA level was positively associated with higher mental and personal wellbeing, lower social isolation, higher perceived attainment, and higher perceived employability. Students that are more physically active tend to report better outcomes across these measures. Considering the important transitional period that university represents for many young adults, approaches to encourage and facilitate engagement in PA should be considered. PA is widely considered to promote health and wellbeing, and the 
results here suggest it may be associated with wider benefits for students including reduced social isolation and improved employability. Indeed, university settings have been suggested to be appropriate for implementation of lifestyle interventions such as PA and thus future work should look to implement and evaluate approaches designed to increase PA levels of university students and the impact they have upon such outcomes.

\section{FUNDING}

The Scottish Active Student Survey was funded by Scottish Student Sport, and the British Active Student Survey was funded by British Universities and Colleges Sport, Scottish Student Sport, and Precor.

\section{REFERENCES}

1. Booth FW, Chakravathy MV, Spangenburg EE. Exercise and gene expression: physiological regulartion of the human genome through physical activity. J Physiol 2002;543(Pt 2):399411

2. Pedersen BK, Saltin B. Exercise as medicine- evidence for prescribing exercise as therapy in 26 different chronic diseases. Scan J Med Sci Sports 2015;3(25):1-72.

3. Elliot CA, Kennedy C, Morgan G, Anderson SK, Morris D. Undergraduate physical activity and depressive symptoms: A national study. Am $J$ Health Behav 2012;36(2):230-241

4. Pate RR, Freedson PS, Sallis JF, Taylor WC, Sirard J, Trost SG, et al. Compliance with physical activity guidelines: prevalence in a population of children and youth. Ann Epidemiol 2002;12:303-308.

5. Leslie E, Fotheringham MJ, Owen N, Bauman A. Age-related differences in physical activity levels of young adults. Med Sci Sports Exerc 2001;33:255258.

6. Nelson MC, Neumark-Stzainer D, Hannan PJ, Sirard JR, Story M. Longitudinal and secular trends in physical activity and sedentary behaviour during adolescence. Pediatrics 2006;118:e1627

7. Plotnikoff RC, Costigan SA, Williams RL, Hutchesson MJ, Kennedy SG, Robards SL, Allen J, Collins CE, Callister R, Germov J. Effectiveness of interventions targeting physical activity, nutrition and healthy weight for university and college students: a systematic review and meta-analysis. Int J Behav Nutr Phys Act 2015;12:45

8. Vankim NA, Nelson TF. Vigorous physical activity, mental health, perceived stress, and socializing among college students. Am J Health Promot 2013;28(1):7-15

9. UCAS. Largest ever proportion of UK's 18 year olds entered higher education in 2017, UCAS data reveals. 2017, https://www.ucas.com/corporate/new s-and-key-documents/news/largestever-proportion-uks-18-year-oldsentered-higher-education-2017-ucasdata-reveals

10. HESA. Students and graduates. 2016: https://www.hesa.ac.uk/data-andanalysis/students

11. Ali M, Yusuf HI, Stahmer J, Rahlenbeck SI. Cardiovascular risk factors and physical activity among university students in Somaliland. $J$ Community Health 2015;40(2):326-330

12. Joseph RP, Royse KE, Benitez TJ, Pekmezi DW. Physical activity and quality of life among university students: exploring self-efficacy, selfesteem, and affect as potential mediators. Qual Life Res 2014;23(2):659-667

13. Deliens T, Deforche B, De Bourdeaudhuij I, Clarys P. Determinants of physical actiuvity and sedentary behaviour in university students: a qualitative study using focus group discussions. BMC Public Health 2015;15:201

14. Department of Health. Start Active, Stay Active: A report on physical activity from the four home countries' Chief Medical Officers. Department for Health, Lonond, UK, 2011: https://assets.publishing.service.gov.u k/government/uploads/system/upload 
s/attachment data/file/216370/dh 12 8210.pdf

15. Dinger MK, Brittain DR, Hutchinson SR. Associations between physical activity and health-related factors in a national sample of college students. $J$ Am Coll Health 2014;62(1):67-74

16. Murphy JJ, MacDonncha C, Murphy MH, Murphy MH, Timperio A, Leech RM, Woods CB. Identification of health-related behavioural clusters and their association with demographic characteristics in Irish university students. BMC Public Health 2019;19:121

17. Pedišić Z, Rakovac M, Titze S, Jurakić, Oja P. Domain-specific physical activity and health-related quality of life in university students. Eur J Sport Sci 2013;14(5):492-499

18. Haase A, Steptoe A, Sallis JF, Wardle J. Leisure-time physical activity in university students from 23 countries: associations with health beliefs, risk awareness, and national economic development. Prev Med 2004;39(1):182-190

19. Likus W, Milka D, Bajor G, JachaczŁopata, Dorzak B. Dietary habits and physical activity in students from the medical university of Silesia in Poland. Rocz Panstw Zakl Hig 2013;64(4): 317324

20. Booth JN, Leary SD, Joinson C, Ness AR, Tomporowski PD, Boyle JM, Reilly. Associations between objectively measured physical activity and academic attainment in adolescents from a UK cohort. Br J Sports Med 2014;48(3):265-270

21. Brunton JA, Mackintosh CI. Interpreting university sport policy in England: seeking a purpose in turbulent times? Int $J$ Sport Policy Politics 2017;9(3):377-395

22. Bailey R. Sport, physical activity and educational achievement - towards an explanatory model. Sport in Society 2017;20(7):768-788

23. Griffiths K, Bullough S, Shibli S, Wilson J. The impact of engagement in sport on graduate employability: implications for higher education policy and practice. Int J Sport Policy Politics 2017;9(3):431-451

24. Hills AP, Dengel DR, Lubans DR, Supporting public health priorities: recommendations for physical education and physical activity promotion in schools. Prog Cardiovasc Dis 2015;57(4):368-374

25. Murphy MH, Carlin A, Woods C, Nevill A, MacDonncha C, Ferguson K, Murphy N. Active students are healthier and happier than their inactive peers: The results of a large representative cross-sectional study of university students in Ireland. J Phys Act Health 2018;15(10):737-746

26. Milton K, Clemes S, Bull F. Can a single question provide an accurate measure of physical activity? $\mathrm{Br} J$ Sports Med 2013;47(1):44-48

27. Sport England. Active Lives Adult Survey: May 17/18 Report. Sport England: UK, 2018: https://www.sportengland.org/media/ 13563/active-lives-adult-may-17-18report.pdf

28. Stewart-Brown S, Tennant A, Tennant R, Platt S, Parkinson J, Weich S, Tennant A. Internal construct validity of the Warwick-Edinburgh Mental Wellbeing Scale (WEMWBS): a Rasch analysis using data from the Scottish Health Education Population Survey. Health Qual Life Outcomes 2009;7(7):15

29. Tennant R, Hiller L, Fishwick R, Platt S, Joseph S, Weich S, ... Rutter C. The Warwick-Edinburgh Mental Wellbeing Scale (WEMWBS): development and UK validation. Health Qual Life Outcomes 2007;5(1):63

30. Warwick Medical School WarwickEdinburgh Mental Wellbeing Scale (WEMWBS). 2015: Retrieved from http://www2.warwick.ac.uk/fac/med/re search/platform/wemwbs/

31. NHS Health Scotland. Short Warwick Edinburgh Mental Well-Being Scale (SWEMWBS). University of Warwick and University of Edinburgh, 2008: https://warwick.ac.uk/fac/sci/med/res earch/platform/wemwbs/swemwbs 7 item.pdf 
32. Davoren MP, Fitzgerald E, Shiely F, Perry IJ. Positive mental health and well-being among a third level student population. PLoS One 2013;8(8):e74921

33. Stranges S, Samaraweena PC, Taggart F, Kandala NB, Stewart-Brown S. Major health-related behaviours and mental well-being in the general population: The Health Survey for England. BMJ Open 2014;4(9):e005878

34. Tinkler L, Hicks S. Measuring Subjective Well-being. Office for National Statistics: UK, 2011: https://www.ons.gov.uk/ons/guidemethod/user-guidance/wellbeing/wellbeing-knowledgebank/understandingwellbeing/measuring-subjective-wellbeing.pdf?format=hi-vis

35. Office for National Statistics. Measuring National Well-being, Personal Well-being Across the UK, 2012/13. Office for National Statistics: $\mathrm{UK}$, 2013:

https://webarchive.nationalarchives.g ov.uk/20160107223337/http://www.o ns.gov.uk/ons/publications/rereference-

tables.html?edition=tcm\%3A77327124

36. PROMIS Health Organisation. Social Isolation - Short Form 4a. http://www.healthmeasures.net/admi nistrator/components/com instrumen ts/uploads/PROMIS\%20SF\%20v2.0\%20 -\%20Social\%20lsolation\%204a\%200218-2018.pdf

37. Hahn EA, DeVellis RF, Bode RK, Garcia SF, Castel LD, Eisen SV, Bosworth HB, Heinemann AW, Rothrock N, Cella D, PROMIS Cooperative Group. Measuring social health in the patient-reported outcomes measurement information system (PROMIS): item bank development and testing. Qual Life Res 2010;19(7):10351044

38. Brant R. Assessing proportionality in the proportional odds model for ordinal logistic regression. Biometrics 1990;46(4):1171-1178
39. Scottish Government. Scottish Health Survey. Scottish Government: UK, 2017:

https://www2.gov.scot/Topics/Statisti cs/Browse/Health/scottish-healthsurvey

40. Healthy Ireland. Get Ireland active! National Physical Activity plan for Ireland 2016. Department of Health: Ireland, 2016: http://www.getirelandactive.ie/Profes sionals/National-PA-Plan.pdf

41. Arnett JJ. Emerging adulthood. A theory of development from the late teens through the twenties. Am Psychol 2000;55(5):469-480

42. Gall TL, Evans DR, Bellerose S. Transition to first-year university: Patterns of change in adjustment across life domains and time. $J$ Soc Clin Psychol 2000;19(4):544-567

43. Ekkekakis P, Murri MB. Exercise as antidepressant treatment: Time for the transition from trials to clinic? Gen Hosp Psychiatry 2017;49:A1-A5

44. Baghurst T, Kelley BC. An examination of stress in college students over the course of a semester. Health Promot Pract 2014;15(3):438-447

45. Gill DL, Reifsteck EJ, Adams MM, Shang Y. Quality of life assessment for physical activity and health promotion: Further psychometrics and comparison of measures. Meas Phys Educ Exerc Sci 2015;19(4): 159-166

46. Swanepoel E, Surujlal J, Dhurup M. Attitude towards sport and physical activity, self-esteem, life satisfaction relationships and variations in terms of gender: Perspectives from university students. African J Phys Health Educ Recreat Dance 2015;21(Supplement 1):14-28.

47. Hughes G, Smail O. Which aspects of university life are most and least helpful in the transition to HE? A qualitative snapshot of student perceptions. $J$ Furth High Educ 2015;39(4):466-480

48. Eime RM, Young JA, Harvey JT, Charity MJ, Payne WR. A systematic review of the psychological and social benefits of participation in sport for children and adolescents: informing development of a conceptual model of 
health through sport. Int J Behav Nutr Phys Act 2013;10:98

49. Basch CE. Healthier students are better learners: A missing link in school reforms to close the achievement gap. $J$ School Health 2011;81(10):593-598

50. Ickes MJ, Brown J, Reeves B, Zephyr PMD. Differences between undergraduate and graduate students in stress and coping strategies. Cal J Health Promot 2015;13(1):13-25

51. Murphy JJ, Murphy MH, MacDonncha C, Murphy N, Nevill AM, Woods CB. Validity and reliability of three selfreport instruments for assessing attainment of physical activity guidelines in university students. Meas Phys Educ Exerc Sci 2017;21(3):134141

52. Fosnacht K, Sarraf SA, Howe E, Peck LK. How important are high response rates for college surveys? Rev High Educ 2017;40(2):245-265

53. Saleh A, Bista K. Examining factors impacting online survey response rates in educational research: Perceptions of graduate students. J MultiDisciplin Eval 2017;13(29):63-73 